\title{
View of Computer Application Professional Lifelong Education Service Model Research
}

\author{
Yi QIANG *, Chuan-Guo Al, Haiyan Yu \\ ${ }^{1}$ College of Science, Jiujiang University, Jiangxi, China, \\ ${ }^{2}$ Dalian Jiaotong University, Liaoning, China \\ ${ }^{3}$ College of Science, Jiujiang University, Jiangxi, China, \\ qiangyi79@163.com, 17824543@qq.com,
}

Keywords: Pre-service teacher education, Computer simulation data, Linear change.

\begin{abstract}
High quality systematic pre-service teacher education model laid the foundation for cultivating excellent teachers. Relying on Jiangxi normal big data analysis, with the aid of computer simulation data linear change preliminarily established a standard mode of the system frame. Based on these ideas, combined with the development of education, lifelong education by analyzing current students, and puts forward the lifelong education all-round service mode of normal students.
\end{abstract}

\section{Introduction}

Lifelong education is a kind of full consciousness of sustainable development education, which is one's life, and cover all of human development education, it requires education become effective, convenient integration system of traditional education system, demanding a breakthrough and innovation. While the traditional education has staged characteristics, the life completely is divided into two stages, study and work directly caused the traditional teacher education system by the disadvantages of normal colleges, unity traditional pattern of training teachers to bring education closeness and teachers; source of oneness A single subject education, making the students' basic knowledge enough solid, professional adaptability is weak, the academic level is low; Teachers cultivation objective orientation is not high, too narrow, due to the caliber the limitations of the knowledge, ability and consciousness of innovation, the lack of Teacher education and post-career pre-service training long-term isolation, transgressed the continuity of teacher professional development. Obviously, our traditional teacher education Lifelong education system already cannot adapt to the requirements of teachers education, cannot adapt to the current international teachers' education opening, specialization, integration and diversified development trend.

With the foundation in education, "Education is the foundation of everything, " the revitalization of a nation depends on education, the revitalization. In the whole society to realize "lifelong education", the first to future teachers "lifelong education first students", and this has become the common people. Combined with the development of education, lifelong education by analyzing current students, and puts forward the lifelong education all-round service mode of normal students.

\section{Mathematics Education (Computer Application) Professional Status}

${ }^{2}$ In our country, the normal college is various specialized courses at various levels of training teachers don't education institutions of higher education, not only to cultivating students professional skills and the actual operation ability, but also cultivate their education teaching ability, make its competent for classroom teaching. Normal education courses in teachers' professional knowledge is composed, but also the foundation of system of course of university education manifest pedagogical characteristic of mark courses. The stand or fall of these course master, to a large extent, on the future of education literacy teachers. Teachers' work object is the future of each professional levels don't education teachers, strict professional training of fostering qualified vocational teachers' prerequisite. As traditional school-running mode and concept of education in our normal influence, heavy 
"academic" light "normal sexual" phenomenon is relatively common, teacher education class increasingly prominent, setting mainly manifested in the following aspects.

\section{Education Courses}

Teacher education courses, ignored by the proportion slant generally less Our normal universities have long will normal education professional education courses for the qualitative, while the non-professional proficient in education courses in positioning cause education in vocational teachers edge discipline position in normal colleges, many of the problems common did not give attention. Outstanding performance at education class scheduling less and the course structure is not reasonable.

Teacher education courses in categories for less Gao shi teachers education class normal education still follow set with the old sanmen, compared to normal colleges have some difference except course name outside, offer such as: (profession) (profession) education pedagogy, psychology, subject teaching method, do not embody education courses of sept ember of vocational education features.

\section{Teaching Practice}

Teaching practice and weak Although our country's education courses in normal teachers also have theory and practice lesson, but the universal existence heavy theory, light practice phenomenon, lack of normal education teaching practice for the vocational guidance.

\section{Teaching Methods Current}

Simple teaching methods Current high in the course teaching is still stays in the subject knowledge system as the center stage, teachers mainly USES the lectures method to impart knowledge to students, the course contents abstraction, teaching organization simplification. This teaching method of concept, though notice this principle of theoretical knowledge, but lack of vocational education teaching practice in vocational education students focus and the education teaching practice guidance, go against the actual teaching ability students improve, also hard to mobilize students in learning enthusiasm and initiative.

\section{Curriculum Evaluation}

Curriculum evaluation Curriculum evaluation is the effect of teaching and learning evaluation, its purpose is to test whether to teaching course goal. In our teachers education is often used the way, written examination of some normal mainly examine such as concept, principle, mastered the theoretical knowledge and ignore the professional education teaching ability for students in the examination, this evaluation method not only violated the open education curriculum purpose, it will be difficult to test out the true level students.

\section{Lifelong Education Service Mode of Mathematics Education (Computer Application) Professional}

Lifelong education normal education goal is to train students to have the learners' guide different professional knowledge and skills, and according to the different professional development situation and professional situation to improve their own professional teaching level, on-the-job training teachers into excellent developers.

\section{Pre-Service Education to Normal More Practice Opportunities}

Students need more practice chance, to make them successful transition into the career, cope with teachers' work. "The micro-standard teaching" is to provide the required courses, students in normal through "the micro-standard teaching" taste the taste of a division at the beginning, experience the various teaching mode. "At the early stage of the micro-standard teaching" still only stay in students' teaching itself, teaching organization pose, such traditional skills, innovation of "after micro-standard teaching" criterion with multimedia putted forward for students and for resources, and will provide 
demonstration on a substantial part of the students focus on student skills, so that students learn in the basis of imitated, change and innovation education reform get reflect the teaching skills.

\section{On-The-Job Education for In-Service Teachers More Research Opportunities}

In-service teacher, we advocate for using "action research methods to promote their professional development. Generally speaking, "action research is the request agent (actual workers) to participate in research, requires that the requirements, and both in practice, in order to jointly study and mutual cooperation. We expect through this method, the career development and in-service teacher quality improving together efficiently, through the teacher quality improving of spiral respond to emerge in endlessly theory, knowledge and skills challenge.

In a concrete operation scheme, we plan to some teachers and education related issues for lead, attracting interest of in-service teacher, according to their respective interests division and cooperation, common conduct research, on the one hand can play students' resources advantage, on the other hand also for students' "action research provides channels.

\section{Lifelong Education Mode}

Therefore we construct lifelong education service mode of normal students is shown Fig. 1:

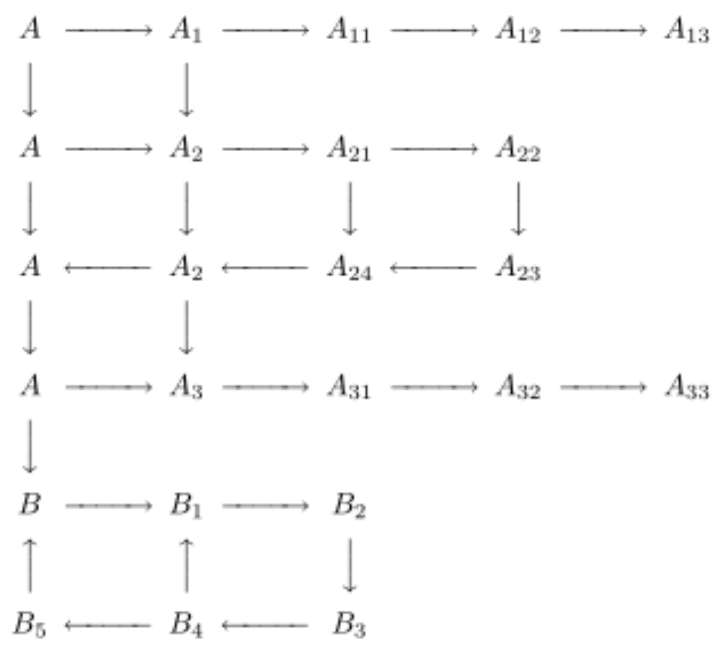

Fig. 1

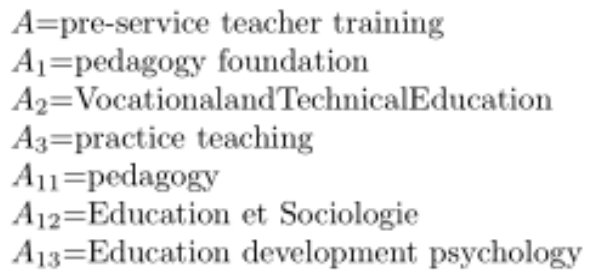




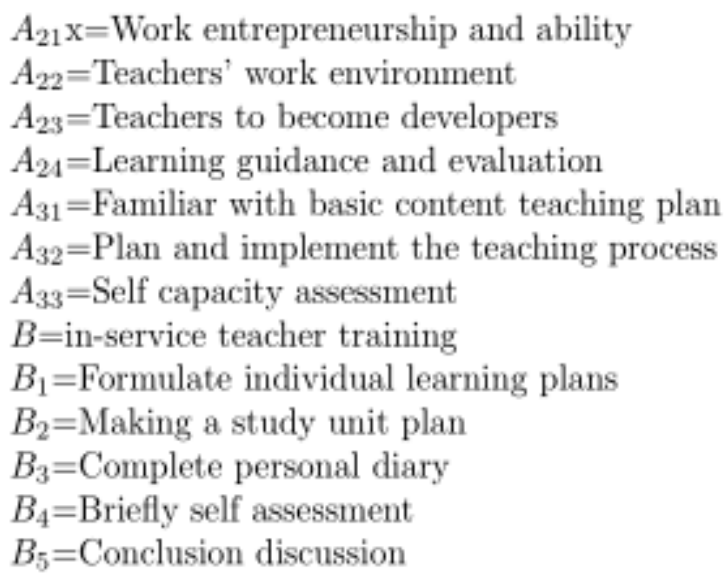

\section{Conclusion}

As lifelong learning become increasingly decided to human survival and development in China, the key factors in constructing life-long education service mode of the teachers in practice has obtained some achievements, but there are also many problems. Lifelong education is a very complicated system, to construct an effective education system, must first lifelong education pattern, clear the current education adjusting and optimizing the structure and form a includes various education type, education form, education mode, education resources, education content, multidimension degree, diversity and multi-level education system of lifelong.

Through open education information platform, lifelong education, can connect various and of all kinds school play social whole advantage, effectively integrate social All kinds of education resources and provide the "one-stop" study support service, provides online and offline, real-time and non-real-time, remote education and traditional campus education combination of hybrid life-long learning service, the realization "everyone learning, always learning, learn to" a vision.

\section{Acknowledgement}

This research was financially supported by Jiangxi province colleges and universities teaching reform research subject $<$ For class under the influence of the elementary school mathematics teaching method, teaching reform research>, serial number: JXJG-15-17-4.

\section{References}

[1]Zhang Ming Xia. Lifelong education and normal education reforms [J] Journal of Shenyang college of education .2003, 5(2)

[2]He Qian. Finland secondary vocational school teachers training mode study [D].Central China Normal University, 2010.

[3]Parl Lengrand. lifelong education introduction.[M] Beijing: Cathay Press,1988.83.

[4]Gu Ming Yuan, Meng Fan Hua. International education new idea [M], Haikou: hainan publishing house, 2001.3.

[5]Lord Robbins. The University in the Modern World [M].Macmillan Company of Canada Limited, 1996.18.

[6]Zhang Xin Sheng. British adult education [M].Jinan: shandong education press, 1993.

[7] WuZunMin.Modern international lifelong education mainly interprets[M] .Shanghai: Shanghai education press, 1999.141. 